\title{
Crescimento de Biótipos de Capim-Arroz em Condição de COMPETIÇÃO ${ }^{1}$
}

\author{
Growth of Barnyardgrass Biotypes under Competition
}

\author{
FERREIRA, E.A. ${ }^{2}$, CONCENÇO, G. ${ }^{3}$, ASPIAZU, I. ${ }^{3}$, SILVA, A.A. ${ }^{4}$, GALON, L. ${ }^{3}$, SILVA, A.F. ${ }^{5}$, \\ FERREIRA, F.A. ${ }^{4}$ e NOLDIN, J.A. ${ }^{6}$
}

\begin{abstract}
RESUMO - Objetivou-se com este trabalho avaliar o crescimento de biótipos de capim-arroz resistente (R) e suscetivel (S) ao herbicida quinclorac em competição entre biótipos e dentro do mesmo biótipo. Para isso, plantas de biótipos de capim-arroz $\mathrm{R}$ e $\mathrm{S}$ ao quinclorac foram cultivadas em diferentes arranjos na unidade experimental. Os tratamentos foram dispostos no esquema fatorial $2 \times 6$, com quatro repetições, em delineamento experimental completamente casualizado. Aos 45 dias após emergência, determinou-se a área foliar e massa seca da parte aérea, separados em folhas e colmos; calculou-se a seguir a taxa de crescimento (TC), área foliar específica (AFE), indice de área foliar (IAF), razão de peso foliar $(\mathrm{RPF})$ e razão de área foliar (RAF). Para as variáveis massa seca, taxa de crescimento, indice de área foliar, razão de peso foliar e razão de área foliar, não foram observadas diferenças entre os biótipos R e S, independentemente do arranjo de semeadura. Entretanto, o biótipo $\mathrm{S}$ apresentou maior área foliar específica que o R quando cultivado isoladamente, como em comunidade. Não houve diferenças marcantes entre os biótipos $\mathrm{R}$ e $\mathrm{S}$ ao herbicida quinclorac quanto ao potencial de crescimento em condição de competição.
\end{abstract}

Palavras-chave: Echinochloa sp., resistência, herbicidas.

\begin{abstract}
The objective of this work was to evaluate the growth of barnyard grass biotypes resistant and susceptible to the herbicide quinclorac, under competition between plants of the same and opposite biotypes. Plants of both biotypes were grown in different proportions in the experimental units. The treatments were arranged in a factorial scheme $2 \times 6$, with four replications in a completely randomized block design. Forty-five days after emergence, the leaf area and dry mass of the shoots were determined, sorted out into leaves and shoots. Growth rate (TC), specific leaf area ( $A F E$ ), leaf area index (IAF), leaf weight rate (RPF) and leaf area rate (RAF) were calculated. The variables dry mass, growth rate, leaf area index, leaf weight rate and leaf area rate did not differ between the biotypes, independently of the treatment evaluated. However, the susceptible biotype was superior to the resistant one in relation to the specific leaf area, both isolated or in community. It was concluded that only discrete differences occur between biotypes resistant and susceptible to the herbicide quinclorac in relation to growth potential under competition.
\end{abstract}

Keywords: Echinochloa sp., resistance, herbicide.

1 Recebido para a publicação em 3.9.2007 e na forma revisada em 26.4.2008.

2 Pós-Doutorado do Dep. de Fitotecnia da Universidade Federal de Viçosa - UFV, Bolsista CNPq, Viçosa-MG <evanderalves@yahoo.com.br>; ${ }^{3}$ Doutorando em Fitotecnia, Bolsista CNPq - UFV; ${ }^{4}$ Professores do Dep. de Fitotecnia, DFT - UFV, Bolsista CNPq; ${ }^{5}$ Mestrando em Fitotecnia, DFT - UFV, Bolsista CNPq; ${ }^{6}$ Pesquisador da EPAGRI, área de plantas daninhas, Itajaí-SC.

Planta Daninha, Viçosa-MG, v. 26, n. 4, p. 799-805, 2008 


\section{INTRODUÇÃO}

A cultura do arroz do irrigado tem grande expressão econômica nos Estados do Rio Grande do Sul e de Santa Catarina, com patamares de produtividade em torno de 5,6 e 7,5 $\mathrm{t} \mathrm{ha}^{-1}$, respectivamente (Andres \& Machado, 2004). As plantas daninhas são responsáveis por perdas substanciais de produtividade das lavouras arrozeiras quando não manejadas adequadamente, em razão da diversidade de espécies presentes nas lavouras, aliada à alta infestação, ao acamamento da cultura e à dificuldade de controle (Fleck et al., 2004).

O capim-arroz (Echinochloa spp.), por estar amplamente distribuído, aliado à elevada competitividade com a cultura do arroz e ao fato de mostrar similaridade morfofisiológica com as plantas de arroz, apresenta dificuldade de controle, seja ele químico, com uso de herbicidas, ou outros métodos alternativos (Andres et al., 2007). O capim-arroz é considerado a segunda espécie daninha mais problemática da cultura do arroz irrigado, podendo reduzir em até $90 \%$ o rendimento de grãos do cereal (Melo et al., 2006).

Dentre os herbicidas utilizados na lavoura de arroz, destaca-se o quinclorac, por reunir flexibilidade na aplicação (pré ou pós-emergência), eficiência de controle das espécies de Echinochloa spp. e Aeschynomene spp., baixa toxicidade ao homem e aos animais e seletividade à cultura do arroz (Andres et al., 2002a). A utilização do quinclorac nas lavouras orizícolas do Rio Grande do Sul e de Santa Catarina iniciou-se na década de 1990, sendo utilizado intensamente até a ocorrência da resistência do capim-arroz a esse herbicida (Menezes \& Ramirez, 2000; Andres et al., 2002b). Muitos agricultores continuaram a realizar o controle do capim-arroz das lavouras de modo inadequado, com uso contínuo de herbicidas com mesmo mecanismo de ação, ausência de rotação de culturas e de herbicidas, não-limpeza das máquinas de colheita e de preparo do solo e da semeadura, entre outros. Atualmente, biótipos de capim-arroz resistentes ao herbicida quinclorac encontram-se dispersos por toda a região Sul do Brasil (Andres et al., 2007).

Nos ecossistemas agrícolas, as plantas daninhas com freqüência apresentam vantagem competitiva em relação às cultivadas. Os programas de melhoramento genético têm procurado desenvolver cultivares que, com pequeno porte e pouco crescimento vegetativo, apresentem elevado acúmulo de fotoassimilados nas sementes, frutos, tubérculos ou outras partes de interesse econômico. Com freqüência, esse acréscimo na produtividade das espécies cultivadas é acompanhado por decréscimo no potencial competitivo (Pitelli, 1985).

A competição das culturas com as plantas daninhas ou entre biótipos da mesma espécie existentes em um local acontece principalmente pelos recursos água, luz e nutrientes (Radosevich et al., 1997). Essa capacidade competitiva que uma planta apresenta sobre a outra pode afetar a quantidade e a qualidade da produção, bem como a eficiência de aproveitamento dos recursos do ambiente. Essas diferenças na capacidade competitiva entre biótipos normalmente está relacionada a características fisiológicas, associadas ao uso da água pelas espécies vegetais (Sinclair et al., 1975; Melo et al., 2006).

Objetivou-se com o trabalho avaliar o potencial de crescimento de biótipos de capimarroz resistente e suscetivel ao herbicida quinclorac, em condição de competição entre os biótipos e as plantas do mesmo biótipo.

\section{MATERIAL E MÉTODOS}

O trabalho foi realizado em casa de vegetação climatizada, mantendo-se a temperatura interna entre 22 e $27^{\circ} \mathrm{C}$ e iluminação natural. As unidades experimentais constaram de recipientes plásticos com área de $0,07 \mathrm{~m}^{2}$, perfurados, contendo $10 \mathrm{~L}$ de solo, corrigido e adubado de acordo com resultado de análise química e recomendações para a cultura. Os tratamentos consistiram do cultivo de uma planta do biótipo de capim-arroz resistente $(R)$ ou do suscetivel (S) ao herbicida quinclorac no centro da unidade experimental (vaso) em competição $\operatorname{com} 0,1,2,3,4$ ou 5 plantas do biótipo oposto ao cultivado no centro da parcela, semeados na periferia de cada unidade experimental (vasos).

A área de semeadura do biótipo central da unidade experimental foi delimitada por cilindro com $5 \mathrm{~cm}$ de diâmetro e $1,0 \mathrm{~cm}$ de profundidade, para facilitar a posterior identificação 
da planta e de seus perfilhos. O cilindro foi inserido no solo, com a borda superior rente à superficie, permitindo total desenvolvimento das raízes e da parte aérea da planta e a plena competição do biótipo central com as demais plantas da periferia, tanto na parte aérea como no sistema de raízes.

O experimento foi realizado em delineamento experimental completamente casualizado, em esquema fatorial $2 \times 6$, com quatro repetições. As unidades experimentais (vasos) foram mantidas eqüidistantes, de forma que a área de superficie disponivel para o desenvolvimento das plantas correspondesse à área da unidade experimental. No momento da colheita, aos 45 dias após semeadura, foi avaliada a área foliar da planta central e de uma planta externa. A massa seca da parte aérea e das raízes das plantas de capim-arroz $\mathrm{R}$ e $\mathrm{S}$ foi determinada por pesagem em balança analitica após secagem das plantas, até massa constante, em estufa de circulação forçada de ar, mantida em temperatura de $70{ }^{\circ} \mathrm{C}$. Tomandose como base os dados obtidos, foram calculados: taxa de crescimento da cultura (MSf/ Ndias - g plantas ${ }^{-1} \mathrm{~m}^{-2}$ ), em que MSf é a massa seca final e Ndias é o número de dias entre o plantio e a colheita das plantas; área foliar específica $\left(\mathrm{A}_{\mathrm{f}} / \mathrm{MS}_{\mathrm{f}}-\mathrm{m}^{2} \mathrm{~g}^{-1}\right)$; indice de área foliar (Af/St), indicando qual a área de folhas por $\mathrm{m}^{2}$ de solo; razão de peso foliar (MSfolhas/ MStotal), indicando a participação das folhas na constituição total das plantas; e razão de área foliar (Af/MSt $-\mathrm{cm}^{2} \mathrm{~g}^{-1}$ ), que é uma estimativa da capacidade de interceptação da radiação pela cultura.

Os dados foram submetidos à análise de variância pelo teste $\mathrm{F}$, utilizando-se o programa estatístico Winstat 2.1 (Machado et al., 2002). Para avaliar o efeito do aumento na densidade de plantas empregou-se o teste de Duncan, enquanto as diferenças entre os biótipos $\mathrm{R} \mathrm{e} \mathrm{S} \mathrm{em} \mathrm{cada} \mathrm{tratamento} \mathrm{foram} \mathrm{avaliadas} \mathrm{pelo}$ teste da Diferença Mínima Significativa (DMS). Em todos os testes efetuados adotou-se o nivel de $5 \%$ de probabilidade de erro.

\section{RESULTADOS E DISCUSSÃO}

Não foram observadas diferenças significativas no acúmulo de massa seca entre biótipos (Tabela 1). Resultado semelhante foi observado
Tabela 1 - Massa seca da parte aérea (MSPA - g planta-1) dos biótipos de capim-arroz resistente e suscetível ao herbicida quinclorac em condição de competição

\begin{tabular}{|c|c|c|c|}
\hline \multirow{2}{*}{$\begin{array}{c}\text { Posição e número } \\
\text { de plantas }\end{array}$} & \multicolumn{2}{|c|}{ Massa seca } & \multirow{2}{*}{ Diferença ${ }^{1 /}$} \\
\hline & Resistente & Suscetível & \\
\hline \multicolumn{4}{|l|}{ Centro $^{3 /}$} \\
\hline $1(0)$ & $17,83 \mathrm{a}^{\mathrm{a}^{\prime} /}$ & $13,71 \mathrm{~b}$ & $+4,12 \mathrm{~ns}$ \\
\hline $1(1)$ & $18,17 \mathrm{a}$ & $21,72 \mathrm{a}$ & $-3,54 \mathrm{~ns}$ \\
\hline $1(2)$ & $6,01 \mathrm{~b}$ & $10,95 \mathrm{bc}$ & $-4,94 \mathrm{~ns}$ \\
\hline $1(3)$ & $7,12 \mathrm{~b}$ & $7,79 \mathrm{~cd}$ & $-0,67 \mathrm{~ns}$ \\
\hline $1(4)$ & $5,78 \mathrm{~b}$ & $4,30 \mathrm{~d}$ & $+1,49 \mathrm{~ns}$ \\
\hline $1(5)$ & $3,99 \mathrm{~b}$ & $4,21 \mathrm{~d}$ & $-0,22 \mathrm{~ns}$ \\
\hline \multicolumn{4}{|l|}{ Externas $^{4 /}$} \\
\hline $0(1)$ & - & - & -- \\
\hline $1(1)$ & $20,86 \mathrm{a}$ & $14,44 \mathrm{~b}$ & $+6,43 *$ \\
\hline $2(1)$ & $13,62 \mathrm{~b}$ & $21,93 \mathrm{a}$ & $-8,32 * *$ \\
\hline $3(1)$ & $11,03 \mathrm{~b}$ & $17,66 \mathrm{ab}$ & $-6,63 *$ \\
\hline $4(1)$ & $11,00 \mathrm{~b}$ & $15,10 \mathrm{~b}$ & $-4,10 \mathrm{~ns}$ \\
\hline $5(1)$ & $10,11 \mathrm{~b}$ & $14,90 \mathrm{~b}$ & $-4,79 \mathrm{~ns}$ \\
\hline \multicolumn{4}{|c|}{$\begin{array}{l}1 / \text { ns }- \text { não-significativo; } *^{*}, * \text { significativo a } 5 \text { e } 1 \% \text { de } \\
\text { probabilidade de erro pelo teste da DMS, respectivamente. }\end{array}$} \\
\hline \multicolumn{4}{|c|}{$\begin{array}{l}\text { 2/ Médias seguidas da mesma letra, na coluna e dentro de cada } \\
\text { posição (centro ou externas), não diferem pelo teste de Duncan } \\
\text { a } 5 \% \text { de probabilidade. }\end{array}$} \\
\hline \multicolumn{4}{|c|}{$\begin{array}{l}\text { 3úmero de plantas do biótipo indicado no centro da parcela } \\
\text { competindo com o número de plantas entre parênteses do } \\
\text { biótipo oposto. }\end{array}$} \\
\hline
\end{tabular}

tanto para o biótipo $\mathrm{R}$ no centro da parcela, competindo com diferentes densidades do biótipo $\mathrm{S}$ na periferia, quanto para o biótipo $\mathrm{S}$, competindo com o R. Biótipos localizados no centro da unidade experimental competiam com plantas do biótipo oposto quanto à resistência ao quinclorac. Quando um determinado biótipo estava na periferia, a competição mais intensa ocorreu nas maiores densidades com plantas do mesmo biótipo. Em geral, plantas que produzem maior quantidade de matéria seca causam maior depleção de recursos do meio, podendo resultar na supressão do crescimento de plantas vizinhas (Fleck et al., 2006). A maior parte dos estudos mostra prejuízo para o biótipo $\mathrm{R}$ em relação ao $\mathrm{S}$ a determinado princípio ativo (LeBaron \& Gressel, 1982). Todavia, em condições de campo, é comum observar o dominio dos biótipos resistentes sobre os suscetiveis. Esse efeito pode ser atribuído ao fato de a quase totalidade desses estudos citados 
ser referente à competitividade entre os biótipos $\mathrm{R}$ e S de plantas daninhas dicotiledôneas. Com relação à taxa de crescimento, os dois biótipos, quando localizados no centro da unidade experimental, não diferiram. Entretanto, com o incremento da densidade, observou-se redução na taxa de crescimento em ambos os biótipos (Tabela 2). Para as plantas localizadas na periferia da unidade, observou-se diferença apenas nas menores densidades; nessa situação, o biótipo $\mathrm{S}$ apresentou maior taxa de crescimento. A taxa de crescimento expressa a velocidade média de crescimento ao longo do período de observação.

Nas maiores densidades, o biótipo R apresentou maior área foliar específica, tanto quando competindo com o biótipo $\mathrm{S}$ ou mesmo quando localizado na periferia da parcela, competindo com plantas do mesmo biótipo (Tabela 3). A área foliar específica está relacionada à espessura da folha (Silva et al., 2005).

Tabela 2 - Taxa de crescimento $\left(\mathrm{TC}=\mathrm{MS}_{\mathrm{f}} / \mathrm{N}\right.$ o dias - g plantas $\left.{ }^{1}\right)$ dos biótipos de capim-arroz resistente e suscetível ao herbicida quinclorac em condição de competição

\begin{tabular}{|c|c|c|c|}
\hline $\begin{array}{c}\text { Posição e número } \\
\text { de plantas }\end{array}$ & \multicolumn{2}{|c|}{ Taxa de crescimento } & \multirow{2}{*}{ Diferença ${ }^{1 /}$} \\
\cline { 2 - 3 } Centro $^{3 /}$ & Resistente & Suscetível & \\
\hline $1(0)$ & $0,45 \mathrm{a}^{\underline{2} /}$ & $0,34 \mathrm{~b}$ & $+0,11 \mathrm{~ns}$ \\
\hline $1(1)$ & $0,46 \mathrm{a}$ & $0,54 \mathrm{a}$ & $-0,09 \mathrm{~ns}$ \\
\hline $1(2)$ & $0,15 \mathrm{~b}$ & $0,27 \mathrm{bc}$ & $-0,12 \mathrm{~ns}$ \\
\hline $1(3)$ & $0,17 \mathrm{~b}$ & $0,19 \mathrm{~cd}$ & $-0,02 \mathrm{~ns}$ \\
\hline $1(4)$ & $0,15 \mathrm{~b}$ & $0,11 \mathrm{~d}$ & $-0,04 \mathrm{~ns}$ \\
\hline $1(5)$ & $0,10 \mathrm{~b}$ & $0,10 \mathrm{~d}$ & $0,00 \mathrm{~ns}$ \\
\hline Externas & & & \\
\hline $0(1)$ & -- & -- & \\
\hline $1(1)$ & $0,52 \mathrm{a}$ & $0,36 \mathrm{~b}$ & $+0,16 *$ \\
\hline $2(1)$ & $0,34 \mathrm{~b}$ & $0,55 \mathrm{a}$ & $-0,21 * *$ \\
\hline $3(1)$ & $0,28 \mathrm{~b}$ & $0,44 \mathrm{ab}$ & $-0,165 *$ \\
\hline $4(1)$ & $0,28 \mathrm{~b}$ & $0,38 \mathrm{~b}$ & $-0,10 \mathrm{~ns}$ \\
\hline $5(1)$ & $0,25 \mathrm{~b}$ & $0,37 \mathrm{~b}$ & $-0,12 \mathrm{~ns}$ \\
\hline
\end{tabular}

1/ ns - não-significativo; *,* significativo a 5 e $1 \%$ de probabilidade de erro pelo teste da DMS, respectivamente.

2/ Médias seguidas da mesma letra, na coluna e dentro de cada posição (centro ou externas), não diferem pelo teste de Duncan a $5 \%$ de probabilidade.

3/ Número de plantas do biótipo indicado no centro da parcela, competindo com o número de plantas entre parênteses do biótipo oposto.

4/ Número de plantas do biótipo indicado, competindo entre si e com a planta do biótipo oposto (1) no centro da parcela.
Dessa forma, as plantas de capim-arroz do biótipo $\mathrm{R}$ apresentaram folhas mais espessas (maior área foliar específica) que as do biótipo S quando livres de competição e sob alta intensidade de competição com o mesmo biótipo apenas. Resultados semelhantes foram observados por Ferreira et al. (2008), os quais constataram que biótipos de azevém $\mathrm{S}$ apresentaram maior área foliar específica, além de maior taxa de crescimento e índice de área foliar, que o R. Os autores concluíram que o biótipo $\mathrm{S}$ de azevém apresenta maior adaptabilidade ecológica que o R.

Neste trabalho não se observou diferença entre os biótipos no tocante à razão de peso foliar tanto no centro quando na periferia das parcelas (Tabela 4). Para os dois biótipos, constatou-se queda não-significativa na razão da massa foliar. A razão da massa foliar indica a quantidade de massa seca que as folhas apresentam em relação à massa total da planta.

Tabela 3 - Área foliar específica $\left(\mathrm{AFE}=\mathrm{A}_{\mathrm{f}} / \mathrm{MS}_{\mathrm{f}}-\mathrm{m}^{2} \mathrm{~g}^{-1}\right)$ dos biótipos de capim-arroz resistente e suscetível ao herbicida quinclorac em condição de competição

\begin{tabular}{|c|c|c|c|}
\hline \multirow{2}{*}{$\begin{array}{l}\text { Posição e número } \\
\text { de plantas }\end{array}$} & \multicolumn{2}{|c|}{ Área foliar específica } & \multirow{2}{*}{ Diferença $\mathrm{a}^{\mathrm{1} /}$} \\
\hline & Resistente & Suscetível & \\
\hline \multicolumn{4}{|l|}{ Centro $^{3 /}$} \\
\hline $1(0)$ & $663,4 \mathrm{a}^{2^{2 /}}$ & $305,5 \mathrm{~b}$ & $+357,9 * *$ \\
\hline $1(1)$ & $492,0 \mathrm{ab}$ & $577,1 \mathrm{a}$ & $-85,1 \mathrm{~ns}$ \\
\hline $1(2)$ & $513,8 \mathrm{ab}$ & $425,4 \mathrm{ab}$ & $+88,4 \mathrm{~ns}$ \\
\hline $1(3)$ & $531,9 \mathrm{ab}$ & $429,3 \mathrm{ab}$ & $+102,6 \mathrm{~ns}$ \\
\hline $1(4)$ & $436,2 \mathrm{~b}$ & $262,2 \mathrm{~b}$ & $+174,0 \mathrm{~ns}$ \\
\hline $1(5)$ & $455,6 \mathrm{~b}$ & $299,5 \mathrm{~b}$ & $+156,1 \mathrm{~ns}$ \\
\hline \multicolumn{4}{|l|}{ Externas $^{4 /}$} \\
\hline $0(1)$ & -- & - & \\
\hline $1(1)$ & $489,4 \mathrm{a}$ & $506,6 \mathrm{a}$ & $-17,2 \mathrm{~ns}$ \\
\hline $2(1)$ & $550,2 \mathrm{a}$ & $488,1 \mathrm{a}$ & $+62,1 \mathrm{~ns}$ \\
\hline $3(1)$ & $451,2 \mathrm{a}$ & $396,7 \mathrm{ab}$ & $+54,5 \mathrm{~ns}$ \\
\hline $4(1)$ & $499,8 \mathrm{a}$ & $369,7 \mathrm{ab}$ & $+130,1 \mathrm{~ns}$ \\
\hline $5(1)$ & $496,1 \mathrm{a}$ & $236,0 \mathrm{~b}$ & $+260,1 *$ \\
\hline
\end{tabular}

1/ ns - não-significativo; *,** significativo a 5 e $1 \%$ de probabilidade de erro pelo teste da DMS, respectivamente.

2/ Médias seguidas da mesma letra, na coluna e dentro de cada posição (centro ou externas), não diferem pelo teste de Duncan a $5 \%$ de probabilidade.

3/ Número de plantas do biótipo indicado no centro da parcela, competindo com o número de plantas entre parênteses do biótipo oposto.

4/ Número de plantas do biótipo indicado, competindo entre si e com a planta do biótipo oposto (1) no centro da parcela. 
Logo, maior massa acumulada em folhas deverá refletir em maior área foliar, maior captação de radiação solar e maior capacidade de sombreamento (Melo et al., 2006).

No que se refere à razão de área foliar, não foi observada diferença entre os biótipos, exceto para $R$ quando cultivado isoladamente no centro da parcela (na ausência de competição), com maior razão de área foliar (Tabela 5). Quanto maior a razão de área foliar, maior será a capacidade da planta em interceptar energia luminosa e de sombrear as demais.

Os biótipos $\mathrm{R}$ e $\mathrm{S}$ também não diferiram com relação ao índice de área foliar tanto no centro quanto na periferia da unidade experimental, quando em competição. Em plantas isoladas, o biótipo $\mathrm{R}$ acumulou maior área foliar que o S (Tabela 6). Quanto à massa seca, esta se correlacionou positivamente com a taxa de crescimento da cultura e com o índice de área foliar. Correlação positiva também foi

Tabela 4 - Razão de peso foliar (RPF) dos biótipos de capimarroz resistente e suscetível ao quinclorac em condição de competição

\begin{tabular}{|c|c|c|c|}
\hline \multirow{2}{*}{$\begin{array}{c}\text { Posição e número } \\
\text { de plantas }\end{array}$} & \multicolumn{2}{|c|}{ Razão de peso foliar } & \multirow{2}{*}{ Diferença ${ }^{1}$} \\
\hline & Resistente & Suscetível & \\
\hline \multicolumn{4}{|l|}{ Centro $^{3 /}$} \\
\hline $1(0)$ & $0,56 \mathrm{a}^{2 /}$ & $0,50 \mathrm{a}$ & $+0,06 \mathrm{~ns}$ \\
\hline $1(1)$ & $0,50 \mathrm{ab}$ & $0,44 \mathrm{a}$ & $+0,06 \mathrm{~ns}$ \\
\hline $1(2)$ & $0,47 \mathrm{bc}$ & $0,43 \mathrm{a}$ & $+0,04 \mathrm{~ns}$ \\
\hline $1(3)$ & $0,48 \mathrm{bc}$ & $0,48 \mathrm{a}$ & $0,00 \mathrm{~ns}$ \\
\hline $1(4)$ & $0,40 \mathrm{c}$ & $0,46 \mathrm{a}$ & $-0,06 \mathrm{~ns}$ \\
\hline $1(5)$ & $0,39 \mathrm{c}$ & $0,43 \mathrm{a}$ & $-0,04 \mathrm{~ns}$ \\
\hline \multicolumn{4}{|l|}{ Externas $^{4 /}$} \\
\hline $0(1)$ & -- & - & - \\
\hline $1(1)$ & $0,44 \mathrm{a}$ & $0,52 \mathrm{a}$ & $-0,08 *$ \\
\hline $2(1)$ & $0,47 \mathrm{a}$ & $0,48 \mathrm{ab}$ & $-0,01 \mathrm{~ns}$ \\
\hline $3(1)$ & $0,50 \mathrm{a}$ & $0,47 \mathrm{ab}$ & $+0,03 \mathrm{~ns}$ \\
\hline $4(1)$ & $0,46 \mathrm{a}$ & $0,45 \mathrm{ab}$ & $+0,01 \mathrm{~ns}$ \\
\hline $5(1)$ & $0,49 \mathrm{a}$ & $0,43 \mathrm{~b}$ & $+0,06 \mathrm{~ns}$ \\
\hline
\end{tabular}

1/ ns - não-significativo; *,** significativo a 5 e $1 \%$ de probabilidade de erro pelo teste da DMS, respectivamente.

2' Médias seguidas da mesma letra, na coluna e dentro de cada posição (centro ou externas), não diferem pelo teste de Duncan a $5 \%$ de probabilidade

3/ Número de plantas do biótipo indicado no centro da parcela, competindo com o número de plantas entre parênteses do biótipo oposto.

4/ Número de plantas do biótipo indicado, competindo entre si e com a planta do biótipo oposto (1) no centro da parcela. observada entre a taxa de crescimento e o índice de área foliar, ou seja, quanto maior o indice de área foliar, maior a captação de luz pela planta e o acúmulo de massa. Já a área foliar específica apresentou correlação positiva com a razão de peso foliar, a razão de área foliar e o índice de área foliar. Nesse caso, plantas com folhas mais espessas apresentam também massa e maior capacidade de captação de energia luminosa (Tabela 7).

De modo geral, para a maioria das variáveis analisadas, o biótipo $\mathrm{S}$ foi mais afetado quando em alta competição com plantas do mesmo biótipo do que quando competindo com o biótipo R. Este, por outro lado, foi menos afetado com o aumento na densidade de plantas do mesmo biótipo e mais afetado quando competindo com o biótipo suscetivel ao herbicida quinclorac. Nos tratamentos "Centro 1(1)" e "Externas 2(1)" o biótipo S reagiu à imposição de competição com aumento significativo de

Tabela 5 - Razão de área foliar (RAF) dos biótipos de capimarroz resistente e suscetível ao herbicida quinclorac em condição de competição

\begin{tabular}{|c|c|c|c|}
\hline \multirow{2}{*}{$\begin{array}{c}\text { Posição e número } \\
\text { de plantas }\end{array}$} & \multicolumn{2}{|c|}{ Razão de área foliar } & \multirow{2}{*}{ Diferença $\mathrm{a}^{1}$} \\
\hline & Resistente & Suscetível & \\
\hline \multicolumn{4}{|l|}{ Centro $^{3 /}$} \\
\hline $1(0)$ & $329,3 \mathrm{a}^{\frac{2 /}{1}}$ & $152,4 \mathrm{a}$ & $+176,9 * *$ \\
\hline $1(1)$ & $247,2 \mathrm{~b}$ & $254,0 \mathrm{a}$ & $-6,8 \mathrm{~ns}$ \\
\hline $1(2)$ & $245,6 \mathrm{~b}$ & $169,1 \mathrm{a}$ & $+76,5 \mathrm{~ns}$ \\
\hline $1(3)$ & $256,4 \mathrm{~b}$ & $145,6 \mathrm{a}$ & $+110,8 \mathrm{~ns}$ \\
\hline $1(4)$ & $251,9 \mathrm{~b}$ & $218,9 \mathrm{a}$ & $+33,0 \mathrm{~ns}$ \\
\hline $1(5)$ & $186,7 \mathrm{~b}$ & $214,8 \mathrm{a}$ & $-28,1 \mathrm{~ns}$ \\
\hline \multicolumn{4}{|l|}{ Externas $^{4 /}$} \\
\hline $0(1)$ & - & - & - \\
\hline $1(1)$ & $208,6 \mathrm{a}$ & $261,8 \mathrm{a}$ & $-53,2 \mathrm{~ns}$ \\
\hline $2(1)$ & $263,7 \mathrm{a}$ & $192,7 \mathrm{a}$ & $+71,0 \mathrm{~ns}$ \\
\hline $3(1)$ & $230,1 \mathrm{a}$ & $231,4 \mathrm{a}$ & $-0,5 \mathrm{~ns}$ \\
\hline $4(1)$ & $230,9 a$ & $175,7 \mathrm{a}$ & $+55,2 \mathrm{~ns}$ \\
\hline $5(1)$ & $245,6 \mathrm{a}$ & $161,1 \mathrm{a}$ & $+84,5 \mathrm{~ns}$ \\
\hline
\end{tabular}

$1 / \mathrm{ns}$ - não-significativo; *,** significativo a 5 e $1 \%$ de probabilidade de erro pelo teste da DMS, respectivamente.

2/ Médias seguidas da mesma letra, na coluna e dentro de cada posição (centro ou externas), não diferem pelo teste de Duncan a $5 \%$ de probabilidade

3/ Número de plantas do biótipo indicado no centro da parcela, competindo com o número de plantas entre parênteses do biótipo oposto.

4/ Número de plantas do biótipo indicado, competindo entre si e com a planta do biótipo oposto (1) no centro da parcela. 
Tabela 6 - Índice de área foliar (IAF) dos biótipos de capimarroz resistente e suscetível ao herbicida quinclorac em condição de competição

\begin{tabular}{|c|c|c|c|}
\hline \multirow{2}{*}{$\begin{array}{c}\text { Posição e número } \\
\text { de plantas }\end{array}$} & \multicolumn{2}{|c|}{ Índice de área foliar } & \multirow{2}{*}{ Diferença $^{\underline{1} /}$} \\
\hline & Resistente & Suscetível & \\
\hline \multicolumn{4}{|l|}{ Centro $^{3 /}$} \\
\hline $1(0)$ & $5,80 \mathrm{a}^{-\frac{2}{-}}$ & $3,15 b$ & $+2,65 * *$ \\
\hline $1(1)$ & $5,85 \mathrm{a}$ & $7,18 \mathrm{a}$ & $-1,33 \mathrm{~ns}$ \\
\hline $1(2)$ & $2,17 \mathrm{~b}$ & $1,60 \mathrm{~b}$ & $+0,57 \mathrm{~ns}$ \\
\hline $1(3)$ & $2,39 \mathrm{~b}$ & $1,64 \mathrm{~b}$ & $+0,75 \mathrm{~ns}$ \\
\hline $1(4)$ & $1,43 \mathrm{~b}$ & $1,30 \mathrm{~b}$ & $+0,13 \mathrm{~ns}$ \\
\hline $1(5)$ & $2,27 \mathrm{~b}$ & $1,31 \mathrm{~b}$ & $+0,96 \mathrm{~ns}$ \\
\hline \multicolumn{4}{|l|}{ Externas $^{4 /}$} \\
\hline $0(1)$ & -- & -- & -- \\
\hline $1(1)$ & $5,69 \mathrm{a}$ & $5,49 \mathrm{a}$ & $+0,20 \mathrm{~ns}$ \\
\hline $2(1)$ & $5,09 \mathrm{a}$ & $5,17 \mathrm{ab}$ & $-0,08 \mathrm{~ns}$ \\
\hline $3(1)$ & $3,67 \mathrm{a}$ & $3,50 \mathrm{ab}$ & $+0,17 \mathrm{~ns}$ \\
\hline $4(1)$ & $3,53 \mathrm{a}$ & $3,80 \mathrm{ab}$ & $-0,27 \mathrm{~ns}$ \\
\hline $5(1)$ & $3,70 \mathrm{a}$ & $3,31 \mathrm{~b}$ & $+0,39 \mathrm{~ns}$ \\
\hline
\end{tabular}

1/ ns - não-significativo; *** significativo a 5 e $1 \%$ de probabilidade de erro pelo teste da DMS, respectivamente.

2/ Médias seguidas da mesma letra, na coluna e dentro de cada posição (centro ou externas), não diferem pelo teste de Duncan a $5 \%$ de probabilidade.

3/ Número de plantas do biótipo indicado no centro da parcela, competindo com o número de plantas entre parênteses do biótipo oposto.

4/ Número de plantas do biótipo indicado, competindo entre si e com a planta do biótipo oposto (1) no centro da parcela.

massa, quando comparado à sua respectiva planta isolada (Tabelas 1, 2, 3 e 6). Esse comportamento não foi observado no biótipo $R$. Além disso, o biótipo suscetível foi superior ao resistente ao quinclorac quanto a acúmulo de massa (Tabela 1), taxa de crescimento (Tabela 2) e razão de peso foliar (Tabela 4) sob baixa intensidade de competição. Por sua vez, o biótipo $\mathrm{R}$ apresentou folhas mais espessas $\mathrm{e}$ maior relação folhas/colmos, o que poderia resultar em menor capacidade de alongamento do colmo sob alta competição.

De acordo com os resultados apresentados, pode-se concluir que não existem diferenças marcantes entre os biótipos de capim-arroz resistente e suscetivel ao herbicida quinclorac quanto ao potencial de crescimento em condição de competição. No entanto, com o incremento da densidade de plantas, observou-se redução em todas as variáveis avaliadas.
Tabela 7 - Matriz de correlação entre as variáveis estudadas nos biótipos resistente e suscetível

\begin{tabular}{|c|c|c|c|}
\hline Variáveis & Interação & Variáveis & Interação \\
\hline MS x TCC & $0,99 * *$ & TCC $\mathrm{x}$ IAF & $0,79 * *$ \\
\hline MS x SLA & $0,18 \mathrm{~ns}$ & SLA x LWR & $0,78 * *$ \\
\hline MS x LWR & $0,30 \mathrm{~ns}$ & SLA x LAR & $0,98 * *$ \\
\hline MS x LAR & $0,07 \mathrm{~ns}$ & SLA $x$ IAF & $0,58 *$ \\
\hline MS x IAF & $0,79 * *$ & LWR x LAR & $0,76 * *$ \\
\hline TCC x SLA & $0,18 \mathrm{~ns}$ & LWR x IAF & $0,36 \mathrm{~ns}$ \\
\hline TCC x LWR & $0,30 \mathrm{~ns}$ & LAR $\times$ IAF & $0,50 \mathrm{~ns}$ \\
\hline TCC x LAR & $0,07 \mathrm{~ns}$ & & \\
\hline
\end{tabular}

\section{LITERATURA CITADA}

ANDRES, A. et al. Uso de inibidores de tubulina, de ACCase e de ALS em arroz irrigado para o controle de capim-arroz resistente a quinclorac. In: CONGRESSO BRASILEIRO DA CIÊNCIA DAS PLANTAS DANINHAS, 23., 2002, Gramado. Resumos... Londrina: SBCPD/Embrapa Clima Temperado, 2002a. p. 203

ANDRES, A. et al. Avaliação de ecótipos de capim-arroz resistentes a quinclorac. In: CONGRESSO BRASILEIRO DA CIÊNCIA DAS PLANTAS DANINHAS, 23., 2002, Gramado. Resumos... Londrina: SBCPD/Embrapa Clima Temperado, 2002b. p. 192

ANDRES, A.; MACHADO, S. L. O. Plantas daninhas em arroz irrigado. In: GOMES, A. S.; MAGALHÃES JR.; A. M. (Eds.). Arroz irrigado no Sul do Brasil. Brasília: Embrapa Informação Tecnológica, 2004. p. 457-546.

ANDRES, A. et al. Detecção da resistência de capim-arroz (Echinochloa sp.) ao herbicida quinclorac em regiões orizícolas do sul do Brasil. Planta Daninha, v. 25, n. 1, p. $221-226,2007$.

FERREIRA, E. A. et al. Potencial competitivo de biótipos de azevém (Lolium multiflorum). Planta Daninha, v. 26, n. 2, p. 261-269, 2008.

FLECK, N. G. et al. Manejo e controle de plantas daninhas em arroz irrigado. In: VARGAS, L.; ROMAN, E. S. (Eds.). Manual de manejo e controle de plantas daninhas. Bento Gonçalves: Embrapa Uva e Vinho, 2004. p. 251-321.

FLECK, N.G. et al. Interferência de Raphanus sativus sobre cultivares de soja durante a fase vegetativa de desenvolvimento da cultura. Planta Daninha, v. 24, n. 3, p. $425-434,2006$ 
LeBARON, H. M.; GRESSEL, J. Summary of accomplishments, conclusions, and future needs. In: LeBARON, H. M.; GRESSEL, J. (Eds.). Herbicide resistance in plants. New York: John Wiley \& Sons, 1982. p. 349-362.

MACHADO, A. A. et al. Sistema de análises estatísticas para Windows - WINSTAT (Versão 2.11). Pelotas:

Universidade Federal de Pelotas, 2002.

MELO, P. T. B. S. et al. Comportamento de populações de arroz irrigado em função das proporções de plantas originadas de sementes de alta e baixa qualidade fisiológica. R. Bras. Agroci., v. 12, n. 1, p. 37-43, 2006.

MENEZES, V. G.; RAMIREZ, H. V. Resistance Echinochloa crus-galli L. to quinclorac in flooded in Southern Brazil. In: INTERNATIONAL WEED SCIENCE CONGRESS, 3., 2000, Foz do Iguaçu. Abstracts... Corvallis: IWSS, 2000. p. 140.
PITELLI, R. A. Interferência de plantas daninhas em culturas agrícolas. Inf. Agropec., v. 11, n. 129, p. 16-27, 1985.

RADOSEVICH, S.; HOLT, J.; GHERSA, C. Physiological aspects of competition. In: Weed ecology implications for manegements. New York: John Willey \& Sons, 1997. p. 217-301.

SILVA, A. C. et al. Análise de crescimento de Brachiaria brizantha submetida a doses reduzidas de fluazifop-p-butil. Planta Daninha, v. 23. n. 1, p. 85-91, 2005.

SINCLAIR, T. R. et al. Water use efficiency of field-grown maize during moisture stress. Plant Physiol., v. 56, n. 2, p. $245-249,1975$ 